Article

\title{
From Homes to Assets and From Pioneers to Shareholders: An Evolving Frontier Terminology
}

\author{
Gabriel Schwake \\ Department of Architecture, TU Delft, The Netherlands; g.schwake@tudelft.nl
}

Submitted: 11 July 2021 | Accepted: 25 November 2021 | Published: 31 March 2022

\begin{abstract}
Frontier settlements played a key role in the formation of Israeli society and its territorial project. In the pre-statehood years and during the first decades after the establishment of the state of Israel, settling the frontiers formed one of the main national objectives, securing the nation's control over space while promoting a unified local identity. Appropriately, settlement practices and discourse focused on pioneer rural communities and industrial towns, with a clear emphasis on housing units and residential estates. With the privatisation of the local economy, the national settlement development mechanism was privatised as well, the former state-led enterprise was harnessed to the interests of the market, and the earlier focus on housing was thus replaced by a property-oriented approach. This article studies the transformations in Israeli frontier settlement practices while analysing their changing modes of spatial production and the terminology they relied on. Studying the development process of Tzur-Yitzhak and Harish, two Israeli localities on the border with the occupied Palestinian West Bank, this article demonstrates how they first emerged as small-scale rural settlements and eventually turned into corporate-led projects. Presenting the geopolitical and societal interests behind both case studies, as well as the manner their proposed planning altered over the years, this article illustrates the transforming modes of production and the evolution of the local settlement terminology, demonstrating the shift from a pioneer-oriented to a market-led frontier settlement.
\end{abstract}

\section{Keywords}

frontiers; housing; Israel; Palestine; pioneers; privatisation; terminology; territoriality

\section{Issue}

This article is part of the issue "The Terms of Dwelling: Re-Theorizing Housing Through Architecture" edited by Yael Allweil (Technion-Israel Institute of Technology) and Gaia Caramellino (Politecnico di Milano).

(C) 2022 by the author(s); licensee Cogitatio (Lisbon, Portugal). This article is licensed under a Creative Commons Attribution 4.0 International License (CC BY).

\section{Introduction: Conquering the Frontier}

"The Conquest of the Desert" was the theme of an international exhibition hosted by the state of Israel in 1953, representing the main achievements of its first five years and reflecting its main ideology. The exhibition functioned as a governmental propaganda tool, demonstrating the Israeli "pioneering spirit" as well as its industrial and agricultural accomplishments that developed the local "wilderness" (Gruweis-Kovalsky \& Katz, 2012, p. 173). Conquering this wilderness, as mentioned in the Hebrew name of the exhibition (not desert), has been a dominant concept in Zionist ideology since its inception (Kemp, 1999, pp. 78-80), forming an integral part of the Zionist efforts to "redeem" Palestine through organ- ised purchases, settlement, and agriculture while stimulating a national renaissance in the Jewish historical homeland (Schwake, 2020b, p. 350). Palestine was thus a frontier area to be domesticated by "blooming the desert" (Sufian, 2007, p. 263) while simultaneously fostering the formation of a new national Jewish identity that is spiritually and physically connected to the local landscape. This idea corresponded with the well-known concept of "a land without a people to a people without a land," portraying Palestine as an empty, undeveloped, and unsettled area waiting for redemption (Said, 1979, p. 9). With the focus on creating a shared national identity, it was by the act of settling the "land without people" that the "people without land" would become a nation. 
This article claims that the frontier domestication discourse continued to accompany the national territorial agenda after the establishment of the state of Israel in 1948, all the way into the 21st century. The terminology of this discourse constantly evolved, adapting to the new territorial tools and the modes of production the Israeli geopolitical project relied on. Examining the cases of Tzur-Yitzhak and Harish, this article analyses the transition from a socialist to a post-socialist and neoliberal mode of frontier domestication, and how the focus shifted from relying on houses to relying on properties and from pioneers to investors. Analysing urban plans, architectural drawings, protocols, policy reports, and marketing strategies, this article examines the transforming modes of production the Israeli frontier domestication mechanism relied on and its evolving terminology.

\section{Frontier Domestication}

Before examining the transforming terminology of Israeli settlements, we must first focus on the term frontier. When speaking of frontiers, it is crucial to separate them from borders: While the latter are delineated lines drawn on maps that receive a physical manifestation that defines the juridical boundaries of a political entity, the definition of the first is much more ambiguous. Being areas and not lines, frontiers come in different widths, which either lay between two neighbouring states or form unclaimed territories that have not yet been formally incorporated into an adjacent political entity (Prescott, 1987, pp. 36-40). As such, according to Mbembe (2003), the term "frontier" usually refers to undeveloped and sporadically settled areas which have not yet been colonised, or ones that are settled by indigenous populations the colonising settlers consider as part of the desolate and wild scenery waiting to be settled, tamed, and claimed. The wilderness the Zionist ethos sought to conquer by settling the land without people thus distinctly corresponds with Mbembe's insights.

In the post-Westphalian era of modern states ruling over clearly defined territories, the act of frontier settlement turned into a state-led spatial practice of enforcing juridical control over a certain area and applying its sovereignty (Prescott, 1987, pp. 30-40). Therefore, in modern times, frontier settlement became a nationbuilding tool, intended to delineate borders, forming and an integral part of the state's territoriality, which is the action of bounding space (Elden, 2010, p. 757). This fusion of bounded space and sovereignty is what Agnew (1994, p. 56) referred to as the "territorial trap," which is the transformation of states into containers of societies situated in confined territories. Similarly, Arendt (1951, p. 282) spoke of the western trinity of state-peopleterritory, highlighting the fact that in the nation-state it is only the areas populated by the ruling ethnic group, which is the nation, that enable the state to enforce its sovereignty. Correspondingly, the formation of the post-World War I successor states, as Arendt (1951) noted, was characterised by population exchanges, transfers, and resettlement campaigns, intended to achieve ethnic homogeneity. Consequently, territoriality through ethnic homogeneity creates a zero-sum game, leading states to enact settler-colonial methodologies, where "access to territory," as Wolfe (2006, p. 388) mentioned, forms the "primary motive" to replace one population with another. Building on Prescott (1987), Elden (2010), Agnew (1994), Arendt (1951), Wolfe (2006), and Mbembe's (2003) definitions, we could claim that frontiers are areas that have not yet been incorporated into the trinity of state-people-territory, and by settling them, states are able to impose both their empirical and juridical sovereignty over them (Ron, 2003). Frontiers might be external, beyond the state's official borders, or internal, within them (Yiftachel, 1996), and they might be rural or urban (Pullan, 2011). Nevertheless, they remain exempted from the state's sovereign territory as long as they are not fully domesticated.

Territoriality in the form of frontier domestication takes the shape of an archipelago of enclaves and exclaves, expanding their home political entity. As Weizman (2006) explains, these function as a system of exterritorial settling points and connecting lines, disconnected from the undomesticated frontier surrounding it. This temporary situation remains until the frontier is domesticated and larger populations are able to migrate and inhabit it while incorporating it into their primary origin state. Suitably, as Pullan (2011) claims, domesticating frontiers, even when carried out by outlaws or vigilantes, is a directed activity, controlled by political and economic centres as a means for territorial expansion. Accordingly, the American "wild west" and its affiliation with individualism and personal freedom was a coordinated state of disorder, directed by the growth interests of urban capitalists and their interests to domesticate the western frontier (Hirst, 2005; Turner, 1962). Correspondingly, building on Lefebvre (2009), Brenner and Elden (2009) claim that territoriality is inseparable from the "state mode of production," ensuring constant accumulation through growth (Brenner \& Elden, 2009, p. 365). To understand the mutual relationship between territoriality and the state's modes of production this article examines the transformation of the first and the manner in which it continues serving the latter, focusing on the Israeli geopolitical project, the changing modes of production it relied on, and their corresponding terminology.

\section{Evolving (Israeli) Frontier Terminology}

In Israel, frontier domestication constantly relied on the construction of territorial housing settlements. As I have previously shown, the production mechanism of these settlements significantly transformed, shifting from a socialist to a post-socialist and neoliberal mode of frontier domestication (Schwake, 2020b, 2022). The physical and spiritual role of the frontier was maintained; yet, 
to adapt it to the changing modes of production, its terminology constantly evolved, and while in the early statehood years the discourse focused on terms such as the pioneer and dwelling unit, these gave way to the homeowner and the house, which eventually led to the investor and the asset.

The pioneer and the minimal dwelling unit were an integral part of the pre-statehood frontier settlement efforts, carried out by the various Labour Zionism movements (Figure 1). Small, scattered, and rural-oriented, the pre-statehood settlements served the purpose of rapidly enlarging the area populated by Jews. Simultaneously, they promoted the development of a new, local-based, Jewish identity. The Halutz (XE "Halutz"), the pioneer, was the main executor of these efforts. He was the prototype of the New Jew, an ideologically-motivated, adventurous, and firm character, involved in conquering the wilderness through settlement and farming, constituting the ideal Zionist protagonist and an inverse image to the diasporic Jew, which was usually depicted in anti-Semitic lines as a wan- dering merchant (Kimmerling, 1983). Settling the frontier (XE "Frontier") was thus an act of hagshama (XE "Hagshama"), the fulfilment of one's individual calling as part of the greater national mission.

The pre-statehood frontier settlements were the ideal dormitory of the pioneer, as seen in their spatial arrangement. Promoted by the Socialist-Zionist hegemony, the frontier settlements were rural communal communities. These included mainly the Moshavim and Kibbutzim, which consisted of a public core that contained the main shared functions, depending on the level of communality, surrounded by rings of either private dwellings in the former and shared units in the latter (Schwake, 2020b, 2022). Therefore, despite small spatial nuances, the pioneers and their minimalistic units were the basis of both typologies and their arrangements corresponded with the ambitions for a unified community (Figure 2).

After the establishment of Israel in 1948, the intention of creating a unified identity based on territory continued. However, led by a state with defined borders,

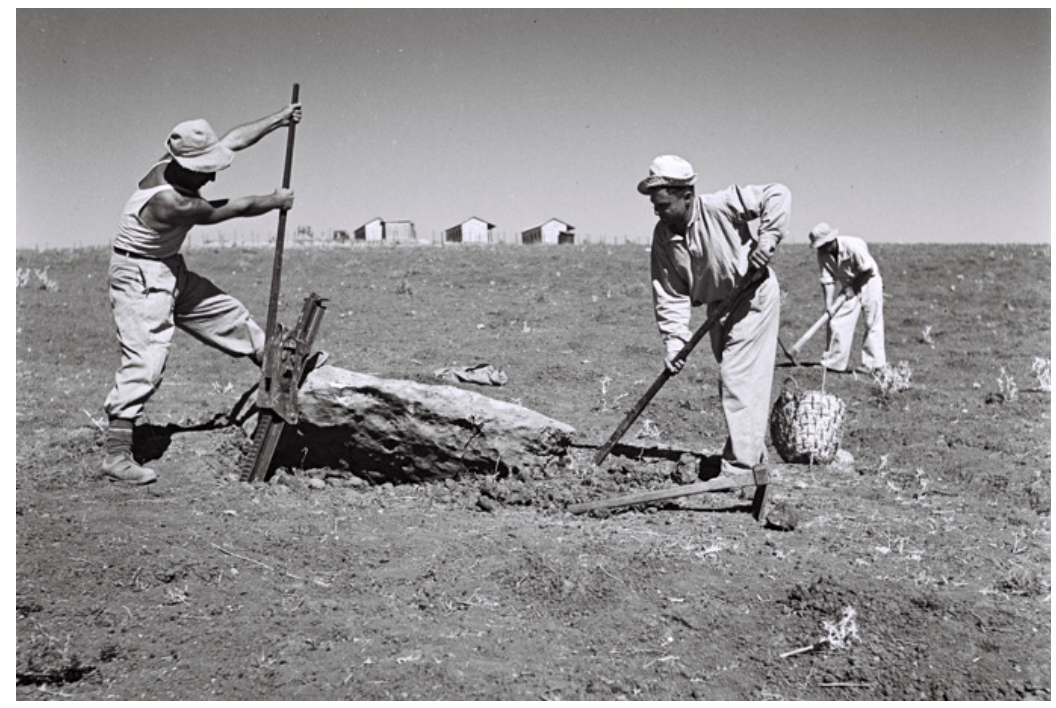

Figure 1. Workers in Kibbutz Gal-On. Source: Kluger (1946).

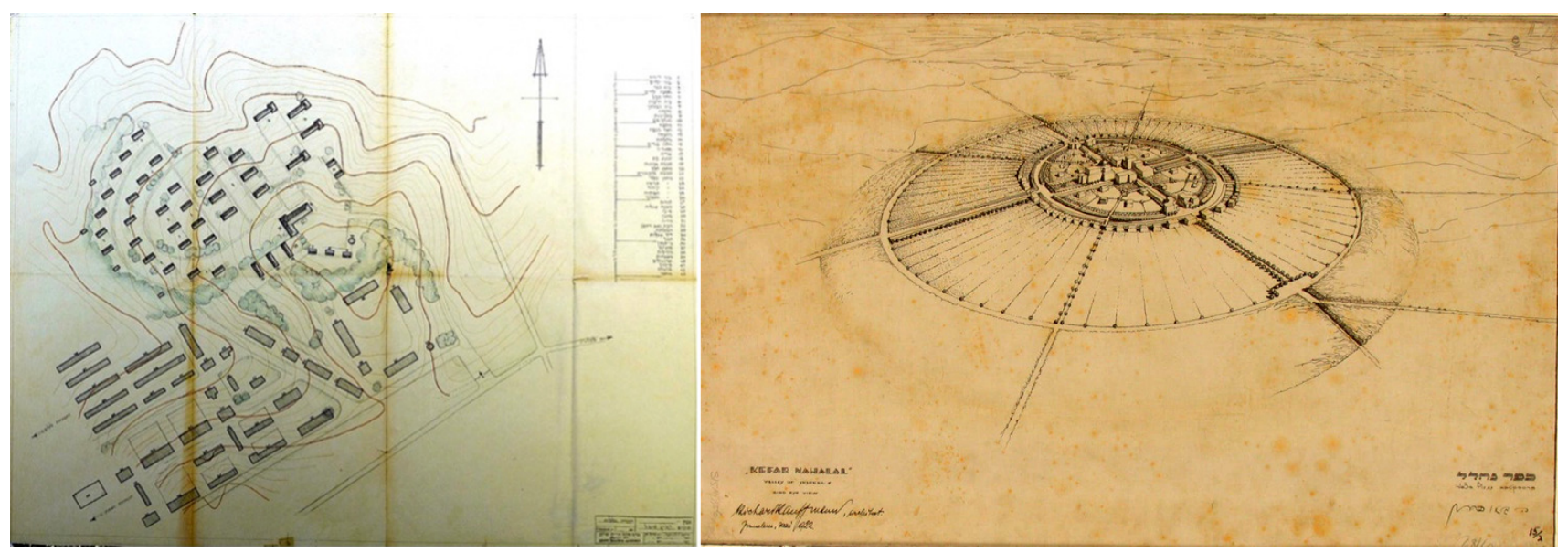

Figure 2. Left: Kibbutz Shoval. Right: Moshav Nahalal. Sources: Sharon (1946) and Kauffmann (1922). 
the focus shifted to what Yiftachel (1996, p. 493) termed as the "internal frontiers" - areas with an Arab majority within Israeli borders, which now needed to be settled by Jews and domesticated. The rural focus was accompanied by a larger, state-directed, and more urban endeavour, seen in the peripheral development towns built throughout the 1950s. Though primarily settled by newly migrating Jews that were not directly affiliated with the ruling Socialist-Zionist hegemony, the development towns reverbed the ideals of pioneering and minimalism, forming an urban- and industry-oriented version of the New Jew and the new state's territorial project (Z. Efrat, 2019, p. 451). Corresponding with the SocialistZionist ideology of the 1950s, in the new medium-scale development towns the focus remained on the communal aspects, consisting of an array of reproduced spartan housing estates, sharing a common public space (E. Efrat, 1994). The pioneer, rural or urban, and his minimalistic dwelling unit, detached or part of a residential estate, were thus the main actors in frontier domestication (Figure 3).

The increasing privatisation of Israel, which began in the late 1960s, shifted the focus towards the homeowner and the detached private house. At the same time, the occupation of the Palestinian West Bank, in 1967, expanded the internal frontiers to be domesticated and provided the needed platform for the new mode of production. Nevertheless, local economic, cultural, and societal changes promoted increasing individualisation and a growing emphasis on private family life (Ram, 2008). Correspondingly, the local mode of spatial development shifted towards suburban outlines with detached family houses (Gonen \& Cohen, 1989). Accordingly, the newly developed territorial settlements followed similar lines, becoming much more suburban and consisting of detached or semi-detached single-family units, enabling a large number of Israelis to pursue the suburban dream of a privately-owned house (Allegra, 2017; Newman, 2017). Applying American-style tract-housing layouts, the communal focus was abandoned and the individual and his private home turned into the main executors of the national territorial agenda (Schwake, 2020 b, 2021, 2022). If earlier the frontier was domesticated by the pioneer, now it was domesticated by the quality-of-life settler, his home, and daily commute (Yacobi \& Tzfadia, 2018). The production and consumption of housing were thus the main means in the national geopolitical project.

Eventually, with growing state-led privatisation, the investor and the asset became the main factors of frontier domestication. To facilitate territorial development in times of increasing neoliberalisation the state began promoting a series of market-oriented measures in order to redirect private capital and stimulate its accumulation in its internal frontiers (Maggor, 2015). Consequently, with the local neoliberal turn, the national territorial mission advanced from the former focus on production and consumption to an emphasis on investment. The private home, therefore, gave way to the asset, and the pioneer was replaced by the investor and speculator. Nevertheless, the new laissez-faire approach continued the territorial terminology that defined the national priority of a certain site according to its ability to enhance Jewish presence, create an Israeli settlement chain, and dismantle Arab sequences (Benvenisti, 1984, p. 29). Therefore, while in the pre-statehood and early statehood years the Israeli territorial project could have been described as a "housing regime" (Allweil, 2016, p. 12), by the 1990s it would be more accurate to define it as a property regime.

Retaining the zero-sum territorial game meant that the frontier domestication approach was maintained and continued to evolve over the years. Accordingly, the various settlements in the occupied Palestinian territories (Allegra et al., 2017; Dalsheim, 2008; Segal \& Weizman, 2003; Weiss, 2011), or within Israel proper (Falah, 1991; Shafir, 2018), continued to follow the focus on achieving territorial dominance through the settlement of Israeli Jews on the expense of Palestinians. In their recent article, Allegra and Maggor (2022) analyse the Israeli
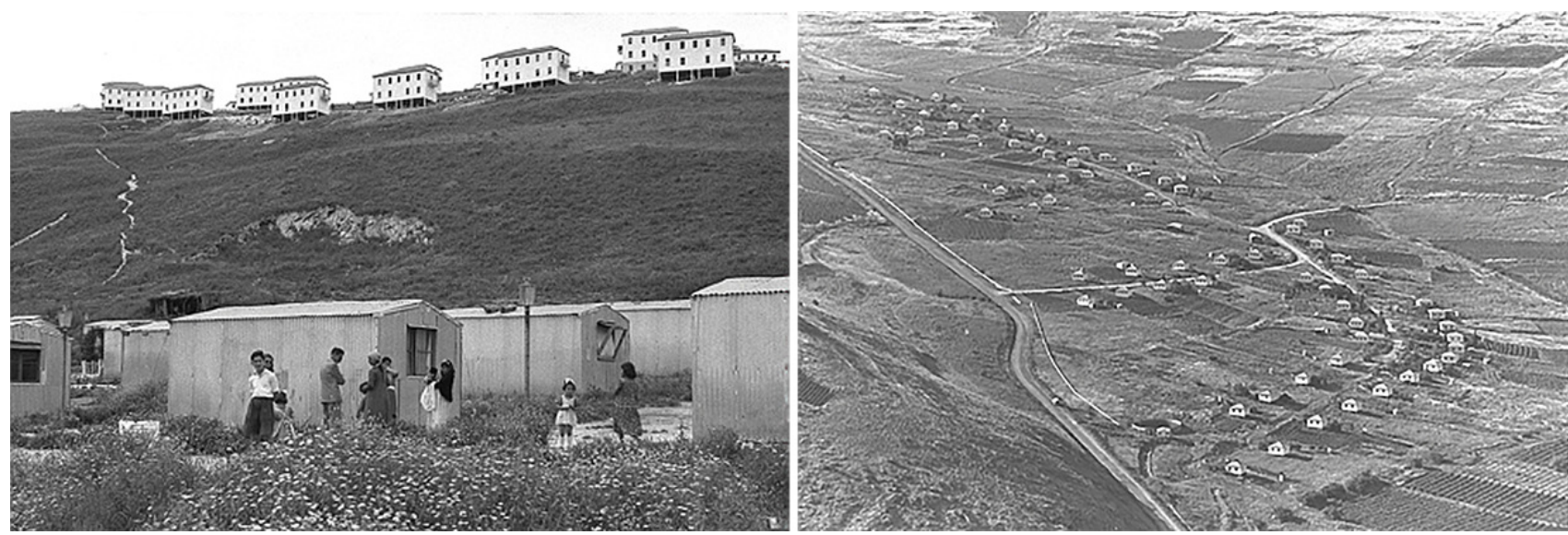

Figure 3. Left: Yokneam development and interim camp for Jewish migrants. Right: Moshv Migdal. Sources: Cohen (1952, 1962). 
settlement campaign in the West Bank since the late 1980 s as a process of metropolitanization. In that sense, if earlier the frontier consisted of the areas that were not cultivated by Jewish farmers, it gradually began turning into the areas not fully incorporated into the main Israeli metropolises and their market-oriented rationale. Tzur-Yitzhak and Harish, the focus of this article, illustrate how this process evolved and how the frontier terminology took shape. Located along the border with the occupied Palestinian West Bank (the Green Line), both sites were an integral part of the state's efforts to secure its control of this frontier area (Figure 4). Gradually, the growing involvement of private capital drastically changed their mode of frontier domestication as well as their residential typologies. Accordingly, what began as small-scale rural-oriented projects, focusing on pioneers and their dwelling units, gave way to suburban settlements and their homeowners and private houses, which were eventually replaced by investors and their assets.

\section{Pioneers and Dwelling Units}

Tzur-Yitzhak and Harish today are market-led developments comprising a hybrid of urban and suburban typologies, yet both were initially rooted in the rural sector. Respectively, they first relied on pioneers and their minimal dwelling units. Tzur-Yitzhak began as an extension of the neighbouring Tzur-Nathan, established in 1966 as a temporary outpost by soldiers from the Nahal Corps, whose military service included settling sites of territorial importance in small groups, referred to as a Gar'in (literally meaning "seed" or "kernel"), managing the construction of the initial infrastructure and the development of agricultural functions before handing it in to a civilian settling group (Douer, 1992, pp. 13-17). Tzur-Nathan was part of a territorial plan initiated in 1960 by the Israeli military in collaboration with the Jewish Agency and the Jewish National Fund, the two main institutions in charge of allocating sites and resources for the estab- lishment of new settlements. The plan was called the "Frontier Fortresses Plan" and included the construction of new rural settlements along the Green Line, which then functioned as the border with Jordan, and was often referred to as the eastern frontier (E. Tal, 2016, p. 14), thus fortifying the defence line through its settlement. Correspondingly, the name Tzur-Nathan literally meant the "Fortress of Nathan," referring to the aforementioned plan on the one hand, and to Nathan Simona Jewish philanthropist from Passaic, New Jersey, who donated to the Jewish Agency and Jewish National Fund-on the other (Figure 5).

The temporary and permanent settings of TzurNathan relied on a pioneer-oriented focus. The transitory site consisted of five prefabricated and minimalistic concrete dwelling units, arranged around a shared public core (The Jewish Agency for Israel, 1974). These were the soldiers' dormitories, clubhouse, and shared kitchen. The buildings were distinctively minimalistic, lacking all ornamentation, decorations, or complexities, forming the ideal dwelling units for their pioneer inhabitants. The transition into a permanent civilian settlement took place in August 1967, shortly after the occupation of the Palestinian West Bank from Jordan, when Israel began controlling both sides of the Green Line. The civilian settling group first occupied the former military units, while the planning and construction of the permanent phase were underway, taking the form of a Moshav Shitufi, a communal agricultural settlement consisting of private households yet with a shared system of supplying means of production and marketing produced goods (The Jewish Agency for Israel, 1969). Accordingly, the planned setting consisted of a shared public area in the middle of the settlement, surrounded by clusters of six private households sharing a common entrance area, with a cooperative zone for workshops and other agricultural functions. A system of pedestrian paths tied the different functions and areas together, making sure the individual households were properly connected to
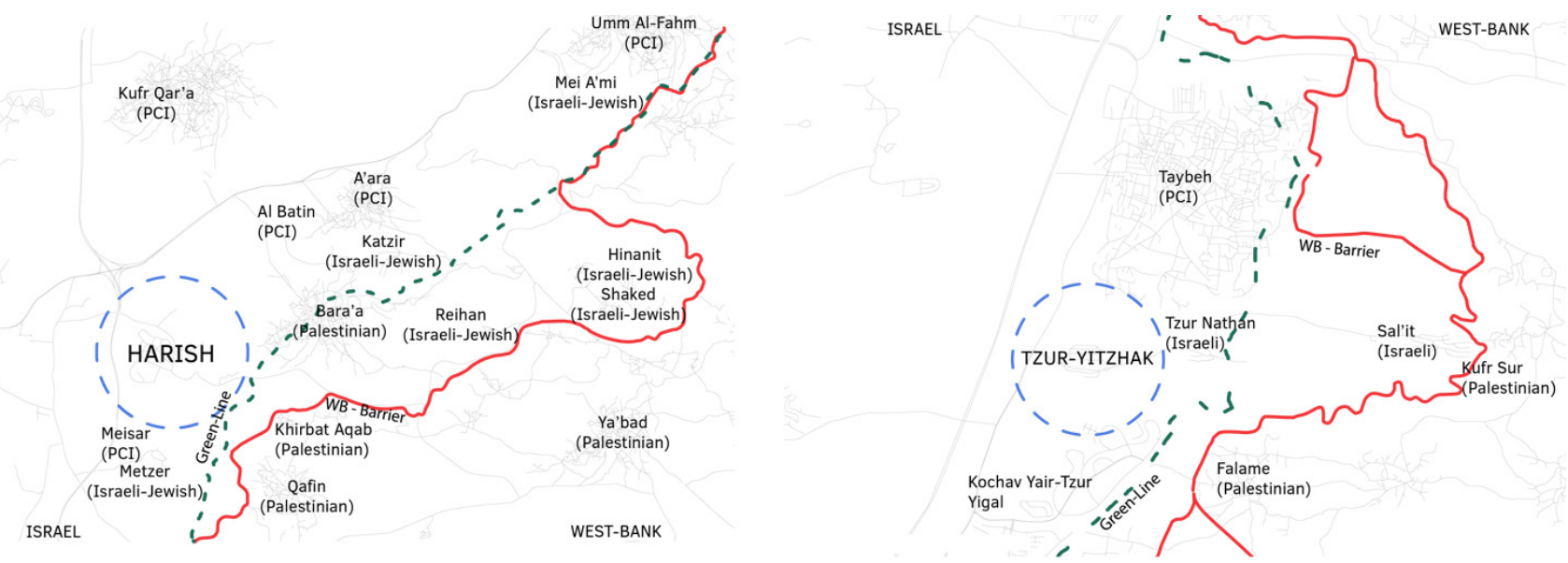

Figure 4. Harish (left) and Tzur-Yitzhak (right) along the Green Line (green, dashed) and the West Bank Barrier (red) in 2015. Note: $\mathrm{PCl}-$ Palestinian citizens of Israel. 


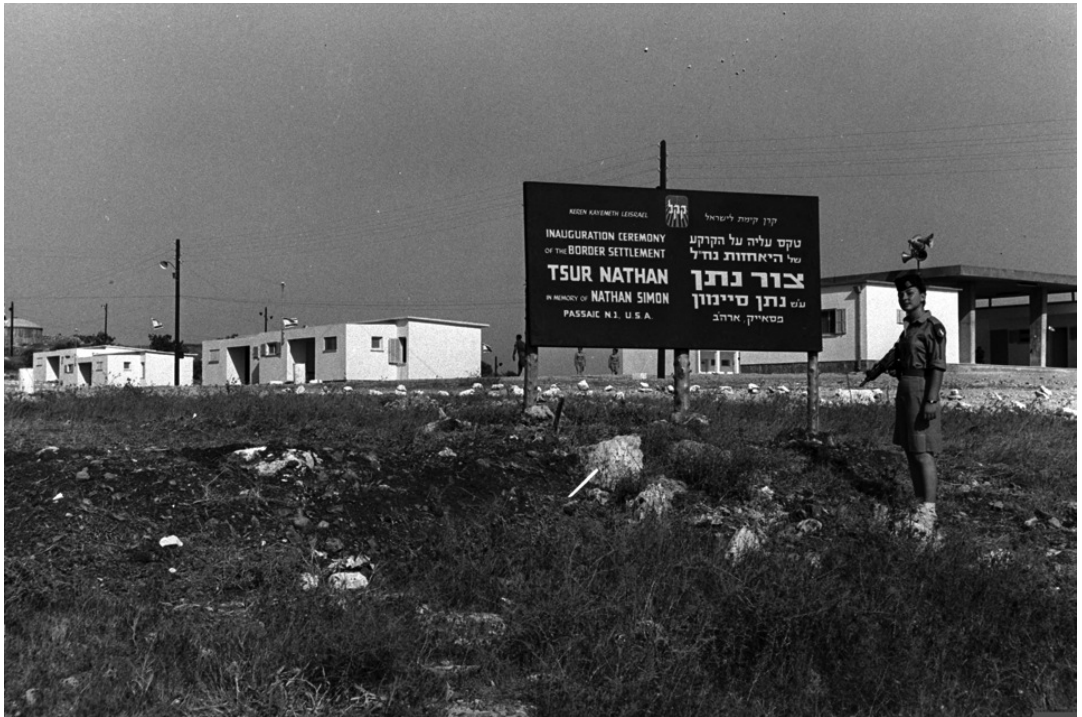

Figure 5. Nahal soldiers in Tzur-Nathan. Source: Milner (1966).

the community while emphasising the public core, which was placed in the settlement's highest point (Figure 6). With the intentions of enhancing Israeli control along the Green Line, the Jewish Agency promoted several plans to expand Tzur-Nathan during the 1970s, extending the rural Moshav westwards towards the current site of Tzur-Yitzhak (Settlement Department, 1977).

Harish was planned almost 15 years after TzurNathan, yet it initially took a much more communal and Spartan character. The settlement site was mentioned in the plans of the Jewish Agency in the late 1970s to strengthen Jewish presence in Galilee and on the eastern side of the Green Line (Schwake, 2020a, pp. 5-6), continuing the efforts of the "Frontier Fortresses Plan" and even including several sites that were mentioned in the 1960s, at that time not yet fully developed (E. Tal, 2016, p. 34). The future site of Harish was coupled with an adjacent spot, forming a territorial wedge intended to prevent the formation of a cross-border Arab connection between the Palestinians living east of the Green Line, and the ones in its west, living in the towns of the Wadi A'ra region inside Israel. Connected to the rural pioneering discourse of frontier domestication the site was given the name Harish, literally meaning "plough," and the neighbouring settlement was named Katzir, literally meaning "harvest" (The Jewish Agency for Israel \& World Zionist Organisation, 1989, pp. 4-10). While Katzir was settled by a civilian group, Harish followed the Nahal course, just like Tzur-Nathan. Correspondingly, the outpost consisted of rows of prefabricated and minimalistic dwelling units placed along the topographic lines, surrounding the clubhouse and communal kitchen which were located on the highest point, emphasising the communal aspects (Figure 7).

Kibbutz Harish represents a more pioneering mode of frontier domestication, despite its later date of

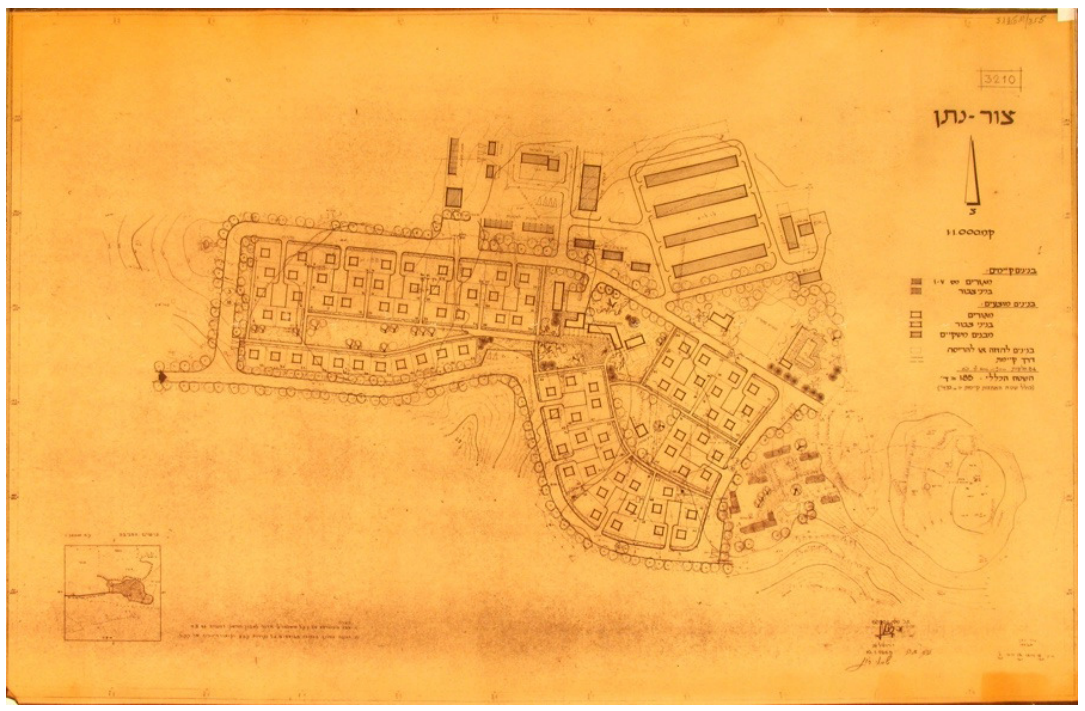

Figure 6. Tzur-Nathan. Source: The Jewish Agency for Israel (1969). 


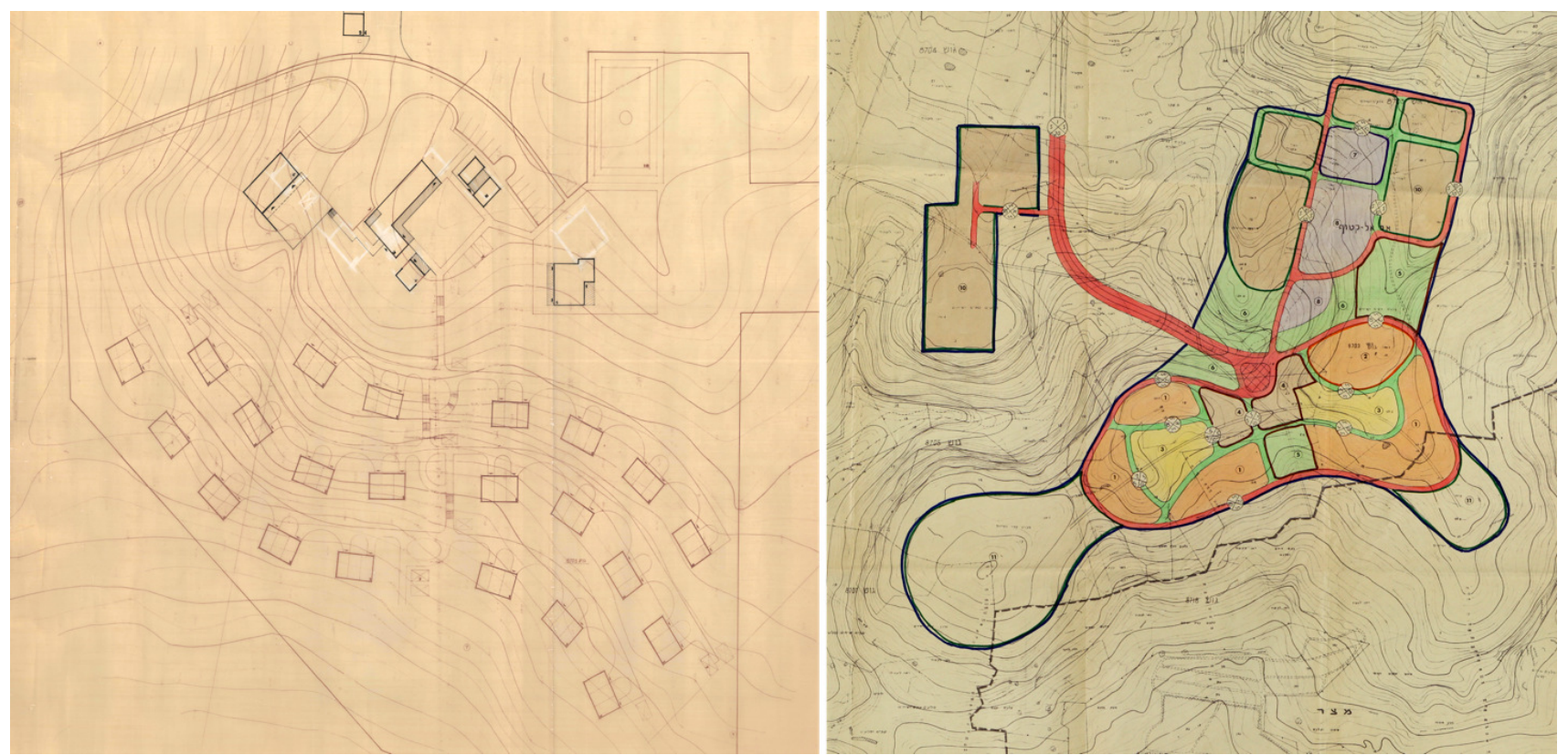

Figure 7. Left: Temporary site of Harish. Right: Outline plan for Kibbutz Harish. Sources: The Jewish Agency for Israel and World Zionist Organisation $(1981,1984)$.

construction. While the soldiers began inhabiting the site and developing the adjacent farming plots, the Jewish Agency and the National Kibbutzim Movement began drafting the plans for the permanent phase. Fitting the promoted communal aspects, the planned layout followed the typical lines of a kibbutz, comprising an open and shared public core that included the main communal functions, which was surrounded by minimalistic dwelling units that were to house the different members. With dwelling units being divided into areas according to the different age groups-couples, singles, youth, and children, all placed on a shared open public space-the setting of Harish matched the pioneering frontier ideals, where the significance of the individuals derived from being part of the community, and not from their distinctive private characters. Nevertheless, Kibbutz Harish lasted only a few years, and the plans for the permanent phase were never realised. The bankruptcy that faced the National Kibbutzim Movement during the 1980s and the inability to find a properly organised settling group put an end to the vision of Harish as a stable communal rural settlement (Schwake, 2020a, p. 6).

The pioneer and rural phase of both sites came to an end in the mid-1980s, shifting to a new mode of production. With the growing emphasis on suburbanisation, as well as the constant decline of the agricultural sector, Harish, and the extension of Tzur-Nathan anticipated a different future. In the 1990s, the state promoted the new "Stars Plan," which included the construction of a series of suburban settlements along the Green Line, replacing the former rural focus of both sites with a new mode of spatial production (Nahoum Dunsky Planners, 1991). Accordingly, the Jewish Agency gave way to the Ministry of Construction and Housing (MCH), transform- ing the mode of frontier domestication discourse and its implementation.

\section{Homeowners and Private Houses}

With the new territorial-suburban vision, the state relied on the production and consumption of real estate as a means to encourage development. Accordingly, in both sites, it endeavoured to promote an image of an attractive settlement with high living standards and persuasive affinity to nature in order to attract "strong" young families, which would grant both projects an appealing image and thus stimulate construction and sales (Tznovar Consultants, 1993, pp. 1-10). Fittingly, the development strategy focused on conducting special sales, targeting a specific type of upper-middle-class potential homeowners by offering them spacious private houses in affordable prices, gentrifying both sites and enabling the continuation of development according to the preferred economic rationale. In that sense, the pioneer gave way to the commuter, a new quality of life settler, domesticating the frontier by turning it into a banal suburban environment of private houses (MCH's Directorate for Rural Construction, 1995a). Neighbouring Katzir, for example, which was merged with Harish into a unified local council named Tel-Eron, went through substantial transformations, turning from a community-oriented ex-urban outpost in the early 1980s into a family-focused suburb, with private parcels and cul-de-sacs a decade later (Figure 8 ).

This gradual process was much more straightforward in Harish and Tzur-Nathan. Kibbutz Harish was evacuated after its failure, turning the site into a clean slate to be planned according to the new mode of production. In Tzur-Nathan, the expansion was originally planned as 


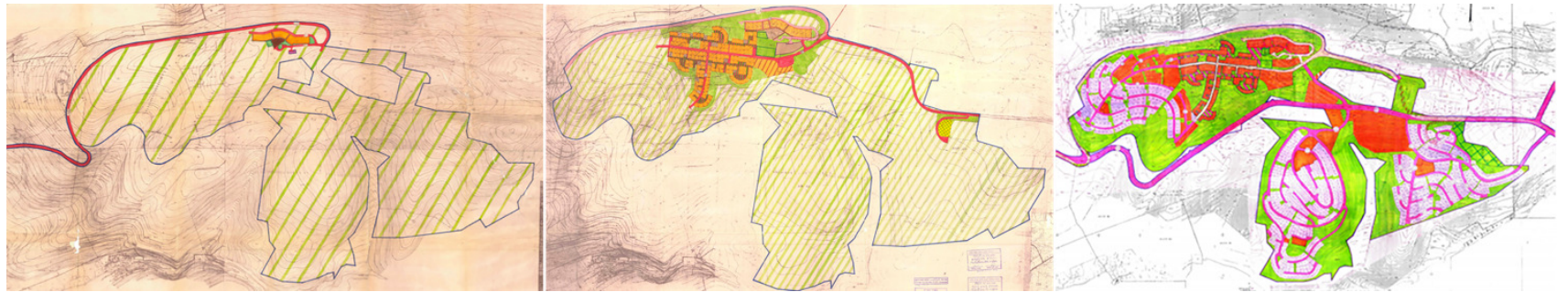

Figure 8. Mitzpe Katzir in 1981, 1985, and 1994. Sources: The Jewish Agency for Israel (1981), Arye Sonino Architects (1985), and Lavi-Bar Architects and Planners (1994).

a direct extension of the rural settlement, yet archaeological findings and land ownership issues prevented the formation of a sequence between the original Moshav and the new project (The Jewish Agency for Israel, 1980). Therefore, here as well, the $\mathrm{MCH}$ enjoyed larger freedom to adapt the new plan to the current mode of production. Accordingly, the $\mathrm{MCH}$ promoted typical suburban layouts, consisting of low-rise and low-density residential environments, with a high emphasis on integrating with the natural landscape (MCH's Directorate for Rural Construction, 1995b). Both layouts were enlarged tract housing settings that resourcefully subdivided the site into smaller parcels to be marketed to private developers and homeowners. With the growing individual focus, areas of public functions that earlier were the focal point in rural and urban settlements were now pushed to the leftover space in the intersection between roads and streets, which due to their irregular shape were of lower economic feasibility and thus comprised the least real estate value; hence, dictating the settlements' hierarchy according to real estate considerations. The homogeneity of the plans continued into the dwelling units. Accordingly, the focus here was on creating reproducible housing compounds, efficiently implemented across the new settlements, and gradually developed, starting with single and double-family houses in the first parts and moving on to the denser three-story and terraced tenements in later phases. Nevertheless, despite the enlarg- ing scale, the denser typologies were to be designed as enlarged private houses, with pitched roofs, separate entrances, setbacks, private gardens, and roof terraces (Figure 9).

Marketing and populating both sites proved to be a troublesome effort to the $\mathrm{MCH}$, causing it to implement new planning approaches and promotion campaigns. In Harish, the $\mathrm{MCH}$ created an oversupply of dwelling units by marketing 300 apartments in medium-density buildings alongside the low-rise private houses. Despite the efforts to attract different high-profile groups and to develop additional low-rise private houses, Harish suffered from a vicious circle of lack of interest and development that put the project on hold for more than a decade (MCH's Urban Planning Department, 1993, p. 2). In Tzur-Yitzhak, the $\mathrm{MCH}$ was more careful, deliberately delaying the project's implementation. Moreover, the state was worried that the newly built dwelling units would attract Palestinian citizens of Israel, which would ironically Arabise both territorial settlements. Therefore, attractive private houses were a doubtful advantage, as they might attract the wrong homeowners, as seen in the case of the Arab Ka'adan family, who after a years-long legal battle were allowed to move to Katzir, a precedent the $\mathrm{MCH}$ was afraid of repeating (Rubenstein, 2000 , pp. 1-2). Therefore, the state began enacting new selective measures by tendering sites to pre-organised housing associations that exclusively existed of Jewish
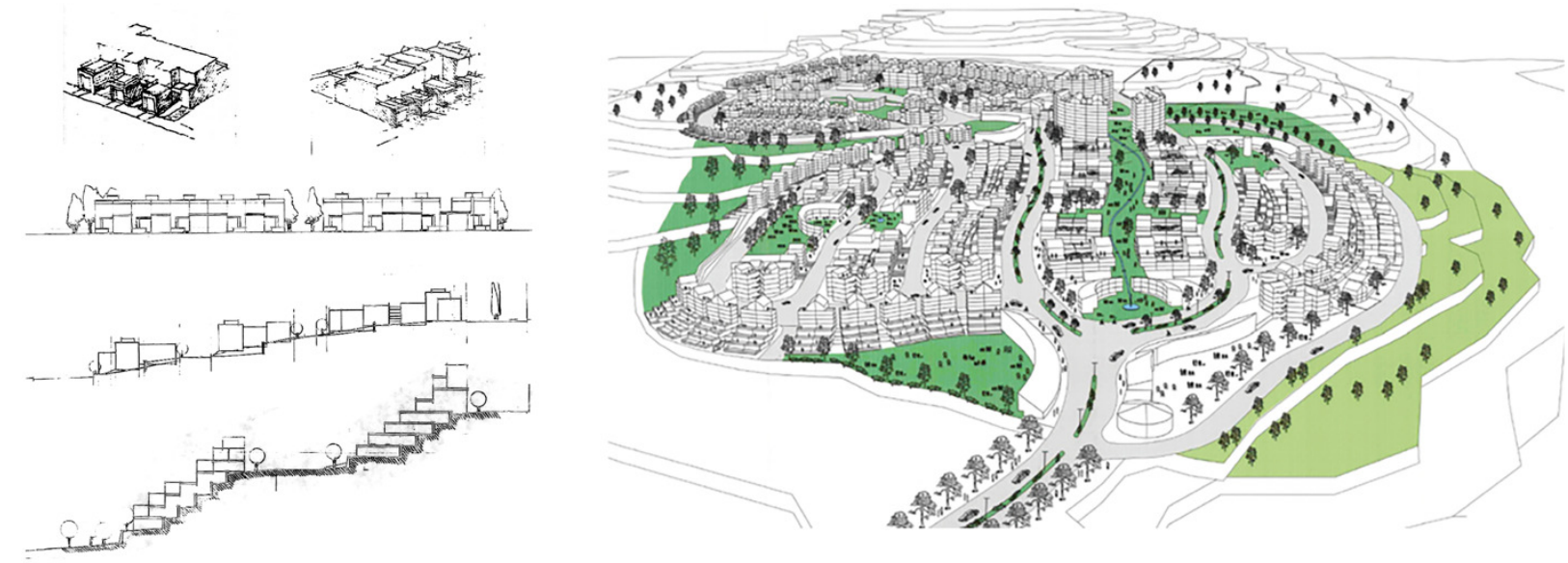

Figure 9. Left: Housing typologies in Harish. Right: Tzur-Nathan project. Sources: Moshe Zur Architects and Planners (1992) and Meir Nir Architects (1997). 
members, such as "The Pioneers of Tzur-Nathan" (Rabin, 1999 , p. 2), or designating Harish as an exclusive ultraOrthodox city (Rubenstein, 2001).

The initial failure of both projects indicates that the $\mathrm{MCH}$ might have rushed in applying a new mode of production, yet instead of relapsing, it chose to enact an even more corporate-led process. Approaching the ultraOrthodox (Haredi) Jewish sector, which is characterised by large and impoverished households, meant that these were now targeted by the $\mathrm{MCH}$ as the new desired homeowners in Harish, and the same goes for the housing associations in Tzur-Yitzhak. The private home, or apartment, and the homeowner remained the main triggers of development, and, to ensure that the homeowner belonged to the pursued ethnic group, the government enacted selective criteria, whether by designating the site to a specific clientele or by marketing parcels to an exclusive housing association. Nevertheless, the dependence on private developers caused the $\mathrm{MCH}$ to start enacting more corporate-oriented measures that would transform the initial suburban-like character of both projects. Harish was separated from Katzir and placed under a special planning committee, while the new scale of construction threatened the rural profile of Tzur-Nathan, causing it to ask for separation from the new project, which the state turned into an independent settlement named Tzur-Yitzhak. Yet, planned on lands leased to Tzur-Nathan, the latter was entitled to one-third of the future dwelling units in the new project (D. Tal, 1999), completing the accurate transformation of the pioneer into an investor.

\section{Investors and Assets}

The post-2008 Israeli housing crisis transformed the national frontier domestication method as the state began relying more on large scale corporations. Due to a sharp increase in property values Israel witnessed an unprecedented rise in real state demand, whether for its use as housing or as an investment (Boruchov, 2018). As a result, peripheral and undesired projects suddenly turned into attractive real estate opportunities. The construction of the Trans-Israel Highway and the completion of the West Bank separation barrier that cut off the area along the Green Line from the occupied Palestinian territories relieved sites like Harish and Tzur-Yitzhak from their marginal affiliation. Therefore, the increasing demand of the middle-class secular Jewish public for dwelling units enabled the $\mathrm{MCH}$ to strictly rely on the private sector.

Consequently, the state enacted a prompt probusiness strategy, intended to attract investment to accelerate development. In Tzur-Yitzhak, the $\mathrm{MCH}$ promoted a series of new adjustment plans meant to tune the approved layout to the "demands of the market" (Cohen Lifshitz Architects, 2008, p. 2). This included redistributing the arrangement of different uses inside the settlement, like changing the location of the settlement's public buildings with the residential parcels that were located near the Arab town of Taybeh and as a result suffered from low interests (Lori, 2011, p. 2). Other amendments included optimising the permitted area of construction by increasing the overall number of apartments and raising the height of buildings while decreasing construction costs and enhancing future incomes, thus remodelling the original vision to ensure profitability (Schwake, 2021, pp. 15-16).

In Harish, the financialised turn began as a turf battle between the ultra-Orthodox and secular sectors. Eventually, after several petitions and court hearings, the general real estate market took over the development of the city and while in the early stages the $\mathrm{MCH}$ relied on privately organised housing associations, this quickly gave way to private developers. To stimulate the pro-investment climate, the $\mathrm{MCH}$ issued a series of new outline planning schemes and even tendered an entire neighbourhood to a single private developer while securing a governmental grant of 1,000,000,000 NIS (approximately 300,000 USD) to encourage development (State Comptroller of Israel, 2016, p. 629). To appease the ultraOrthodox sector, the government dedicated a new city in the southern Negev for its exclusive use, away from the booming real estate market of Harish.

To adapt the layout of Harish to the new financialised mode of production, the $\mathrm{MCH}$ enacted the same measures as in Tzur-Yitzhak. Accordingly, it permitted the increase of the overall number of dwelling units, as well as the allowed height of buildings. The gross density in Harish, meaning the total sum of dwelling units divided by the overall area, was not significantly changed, rising by a mere 20\%, from 2.2 units per dunam to 2.6. Nevertheless, the net density, dwelling units per residential areas, rose by $60 \%$, going from six units per dunam to almost 10 (Mansfeld-Kehat Architects and Planners, 2012; Moshe Zur Architects and Planners, 1992). Accordingly, the alterations in the city's layout were mainly meant to ensure the profitability of investment and to continue the market-oriented approach. With the new financialised mode, the settlements' layout turned into two-dimensional settings intended to maximise profits, creating buildings that are three-dimensional excel sheets of cost-efficiency. Therefore, while earlier plans included some variations, the new plans of the 2000s were based mainly on recreating the same dimensions of a single repetitive parcel (Rubenstein, 2001), eventually leading to the implementation of similar housing typologies across both projects (Figure 10).

As a financialised mode of production, the development of Harish and Tzur-Yitzhak was accompanied by a vast promotion campaign. The first emphasis of the different advertisements colour pieces, and commercials focused on the affordability of apartments in both sites, the usual affinity to nature, and the easy commute to the main metropolitan area. The PR campaign in Harish went further, including a specially designed online platform, as well as an open collaboration with Israel's largest 

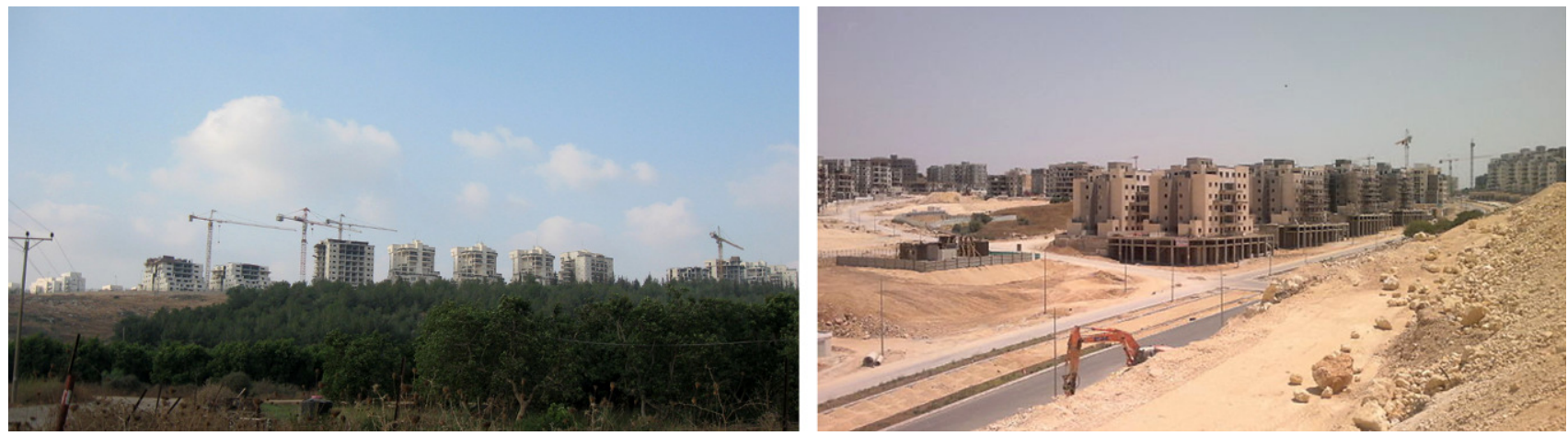

Figure 10. Left: Tzur-Yitzhak, 2010. Right: Harish, 2016. Source: Wikimedia Commons.

news website, Ynet, in a special section called "Building a City" that includes a series of endorsed colour pieces promoting the image of a young and vibrant community. Besides the usual emphasis on education, parks, accessibility, and affordability, even LGBT presence in Harish was cynically used for marketing purposes (Schwake, $2020 a$, p. 10). Yet the most striking tool in the marketing process is the use of the constant increase in real estate prices in both projects, framing an apartment in Tzur-Yitzhak or Harish as a sound investment (Levi \& Bahor-Nir, 2018; Tzur, 2018). While this illustrates an ironic situation where the success of new housing projects initiated by the state to fight increasing prices are measured by increasing prices, it mainly emphasises that in the new financialised mode of production, which seeks to continuously expand development as a means to attract further private investment, the shareholder and speculator replaced the simple homeowner. Not surprisingly, unofficial reports of the $\mathrm{MCH}$ estimate that half of the apartments in Harish were bought as assets by investors (Levi \& Bahor-Nir, 2018; Tzur, 2018), relying upon derivative rents to generate profits, demonstrating the financialisation of the efforts to domesticate the Israeli frontier.

\section{Conclusions}

The frontier, as a concept referring to areas not yet settled or not yet developed, continued to accompany the development of the local built environment even in the 21st century. Nevertheless, the manner in which the frontier was domesticated corresponds with the prevailing socio-economic relations and modes of spatial production. Here it is worth mentioning Lustick's (1993, p. 44) definition of normalising territorial expansion, in which a territory becomes "an integral part of the state, not as a problematically occupied asset... [but when its status becomes] part of the natural order of things for the overwhelming majority of the population." Therefore, the state's geopolitical "territorial strategies" (Allegra \& Maggor, 2022) had to constantly adapt to the dominant geoeconomic rationale of the "production of territory" (Brenner \& Elden, 2009), and rely on a corresponding terminology that ensured it would become "part of the natural order of things." Accordingly, the terminology of frontier domestication and its physical materialisation continuously evolved, shifting the focus from pioneers to homeowners, and from homeowners to investors, while passing from dwelling units to private houses, and from private houses to assets. Nevertheless, this evolution was far from being a smooth and preplanned process but rather consisted of a series of ad hoc decisions intended to repeatedly adapt the state's territorial project to the changing economic, cultural, and social climate. Therefore, as the state began shying away from uncompromising and purely ideological settlement methods, it began politicizing seemingly apolitical endeavours - the real estate market. The decadeslong transition from a quasi-socialist to a privatised and neoliberal mode of spatial production, as seen in Harish and Tzur-Yitzhak, demonstrates how the "free market" is actually a product of state policy, and how the allegedly colour-blind neoliberalism forms a political tool in the zero-sum logic of state-people-territory. Therefore, if Lefebvre's state mode of production is a directed nationalization expansion campaign that commodifies space as a means to facilitate further accumulation (Lefebvre, 2009, p. 233), then in Harish and Tzur-Nathan it was the commodification of space that enabled its nationalization, completing the domestication of the frontier by incorporating it into the state's real estate market.

\section{Acknowledgments}

I would like to thank the Fritz Thyssen Foundation for their support. I would also like to thank the anonymous reviewers for their comments and suggestions, as well as the editors of this thematic issue, Yael Allweil and Gaia Caramellino.

\section{Conflict of Interests}

The author declares no conflict of interests.

\section{References}

Agnew, J. (1994). The territorial trap: The geographical assumptions of international relations theory. 
Review of International Political Economy, 1(1), 53-80.

Allegra, M. (2017). "Outside Jerusalem-Yet so near": Ma'ale Adumim, Jerusalem, and the suburbanization of Israel's settlement policy. In M. Allegra, A. Handel, \& E. Maggor (Eds.), Normalizing occupation: The politics of everyday life in the West Bank settlements (pp. 48-63). Indiana University Press.

Allegra, M., Handel, A., \& Maggor, E. (Eds.). (2017). Normalizing occupation: The politics of everyday life in the West Bank settlements. Indiana University Press.

Allegra, M., \& Maggor, E. (2022). The metropolitanization of Israel's settlement policy: The colonization of the West Bank as a strategy of spatial restructuring. Political Geography, 92, Article 102513. https://doi.org/ 10.1016/j.polgeo.2021.102513

Allweil, Y. (2016). Homeland: Zionism as housing regime, 1860-2011. Routledge.

Arendt, H. (1951). The origins of totalitarianism. Random House.

Arye Sonino Architects. (1985). Outline plan for Katzir. Israel Land Administration.

Benvenisti, M. (1984). The West Bank data project: A survey of Israel's policies. Aei Press.

Boruchov, E. (2018). On target: The housing crisis and damage to the planning system. Planning, 15(2), 63-85.

Brenner, N., \& Elden, S. (2009). Henri Lefebvre on state, space, territory. International Political Sociology, 3, 353-377. https://doi.org/10.1111/j.17495687.2009.00081.x

Cohen, F. (1952). Yokneam development and interim camp for Jewish migrants. Governmental Press Office, Jerusalem, Israel.

Cohen, F. (1962). Moshav Migdal. Governmental Press Office, Jerusalem, Israel.

Cohen Lifshitz Architects. (2008). Urban outline plan $S D / M K / 101 / 15 / 8$. Israel Land Administration.

Dalsheim, J. (2008). Twice removed: Mizrahi settlers in Gush Katif. Social Identities, 14, 535-551.

Douer, Y. (1992). Our sickle is our sword. Yad Tevenkin.

Efrat, E. (1994). New development towns of Israel (1948-93). Cities, 11(4), 247-252.

Efrat, Z. (2019). The object of Zionism: The architecture of Israel. Spector Books.

Elden, S. (2010). Thinking territory historically. Geopolitics, 15(4), 757-761.

Falah, G. (1991). Israeli “Judaization" policy in Galilee. Journal of Palestine Studies, 20(4), 69-85.

Gonen, A., \& Cohen, G. (1989). Multi-faceted screw-up of neighborhoods in Jerusalem. City and Region (Ir Veezor), 19(20), 9-27.

Gruweis-Kovalsky, O., \& Katz, Y. (2012). Taaruchat kibush hashmama: hataarucha hebenleumit harishona beyerushalayim, 1953 [The Conquest of the Desert exhibition and fair, 1953]. Israel, 20, 153-180.

Hirst, P. (2005). Space and power: Politics, war and architecture. Polity Press.
Kauffmann, R. (1922). Nahalal. Central Zionist Archive, Jerusalem, Israel.

Kemp, A. (1999). The frontier idiom on borders and territorial politics in post-1967 Israel. Geography Research Forum, 19, 78-97.

Kluger, Z. (1946). Workers in Kibbutz Gal-On. Governmental Press Office, Jerusalem, Israel.

Kimmerling, B. (1983). Zionism and territory: The socioterritorial dimensions of Zionist politics. Institute of International Studies, University of California, Berkeley.

Lavi-Bar Architects and Planners. (1994). Outline plan for Katzir. Israel Land Administration.

Lefebvre, H. (2009). Space and the state. In N. Brenner \& S. Elden (Eds.), State, space, world (pp. 223-253). University of Minnesota Press.

Levi, D., \& Bahor-Nir, D. (2018, February 2). Harish: Ir lehaskarah [Harish: A city for rent]. Calcalist. https://www.calcalist.co.il/local/articles/0,7340, L-3730631,00.html

Lori, A. (2011, March 2). Mitkefet miflatzot hanadlan nimshechet. Hapaam begirsat Tzur Yitzhak [The strike of real estate monsters continues, this time in the Tzur Yitzhak version]. Haaretz.

Lustick, I. (1993). Unsettled states, disputed lands: Britain and Ireland, France and Algeria, Israel and the West Bank-Gaza. Cornell University Press.

Maggor, E. (2015). State, market and the Israeli settlements: The Ministry of Housing and the shift from messianic outposts to urban settlements in the early 1980s. Israeli Sociology, 16, 140-167.

Mansfeld-Kehat Architects and Planners. (2012). Local outline plan Harish/1/A. Israel Land Administration.

Mbembe, A. (2003). Necropolitics. Public Culture, 15(1), 11-40.

Meir Nir Architects. (1997). Tzur Nathan project. Copy in possession of Meir Nir.

Milner, M. (1966). Nahal soldiers in Tzur-Nathan. Governmental Press Office, Jerusalem, Israel.

Ministry of Construction and Housing's Directorate for Rural Construction. (1995a). Program for Tzur Nathan. [Report]. Ministry of Construction and Housing (ISA-moch-Programs-000upmn). Israel State Archive, Jerusalem, Israel.

Ministry of Construction and Housing's Directorate for Rural Construction. (1995b). The stars settlements. [Report]. Ministry of Construction and Housing (ISA-moch-Programs-000upmn). Israel State Archive, Jerusalem, Israel.

Ministry of Construction and Housing's Urban Planning Department. (1993). Meeting regarding Tel-Eron15.9.1993. [Protocol]. Ministry of Construction and Housing (ISA-moch-Programs-000upmn). Israel State Archive, Jerusalem, Israel.

Moshe Zur Architects and Planners. (1992). Harish. Ministry of Construction and Housing and Israel Land Administration.

Nahoum Dunsky Planners. (1991). Development of the 
hills' axis: The seven stars plan. University of Haifa and Technion-Israeli Institute of Technology.

Newman, D. (2017). Settlement as suburbanization: The banality of colonization. In M. Allegra, A. Handel, \& E. Maggor (Eds.), Normalizing occupation: The politics of everyday life in the West Bank settlements (pp. 24-47). Indiana University Press.

Prescott, J. R. V. (1987). Political frontiers and boundaries. Routledge.

Pullan, W. (2011). Frontier urbanism: The periphery at the centre of contested cities. The Journal of Architecture, 16(1), 15-35. https://doi.org/10.1080/ 13602365.2011.546999

Rabin, D. (1999). Building in Tzur Nathan. [Report]. Ministry of Construction and Housing (ISA-mochCentralRegion-000v5zh). Israel State Archive, Jerusalem, Israel.

Ram, U. (2008). The globalization of Israel. Routledge.

Ron, J. (2003). Frontiers and ghettos: State violence in Serbia and Israel. University of California Press.

Rubenstein, M. (2000). Harish survey. Ministry of Construction and Housing.

Rubenstein, M. (2001). Proposal for the planning of Harish. [Meeting protocol]. Ministry of Construction and Housing (ISA-moch-HaifaRegion-000t76e). Israel State Archive, Jerusalem, Israel.

Said, E. (1979). The question of Palestine. Times Books.

Schwake, G. (2020a). Financialising the frontier: Harish city. Cities, 107, Article 102945. https://doi.org/ 10.1016/j.cities.2020.102945

Schwake, G. (2020b). Settle and rule: The evolution of the Israeli national project. Architecture and Culture, 8(2), 350-371. https://doi.org/10.1080/20507828. 2020.1730624

Schwake, G. (2021). Supply-side territoriality: Re-shaping a geopolitical project according to economic means. Space and Polity, 25, 75-96.

Schwake, G. (2022). Dwelling on the green-line: Privatise and rule in Israel/Palestine. Cambridge University Press.

Segal, R., \& Weizman, E. (2003). The mountain: Principles of building in heights. In R. Segal \& E. Weizman (Eds.), A civilian occupation: The politics of Israeli architecture (pp. 79-99). Verso.

Settlement Department. (1977). Detailed plan $S D / B M / 101 / 15$. The Jewish Agency for Israel and Israel Land Administration.

Shafir, G. (2018). From overt to veiled segregation: Israel's Palestinian Arab citizens in the Galilee. Middle East Studies, 50, 1-22.

Sharon, A. (1946). Kibbutz Shoval. Arieh Sharon Archive.

State Comptroller of Israel. (2016). Local government audit reports.

Sufian, S. (2007). Healing the land and the nation: Malaria and the Zionist project in Palestine, 1920-1947. The University of Chicago Press.

Tal, D. (1999, October 14). Development momentum.
Globes.

Tal, E. (2016). The frontier fortresses plan. University of Haifa.

The Jewish Agency for Israel. (1969). Tzur Nathan. [Map]. (S126M8553). Central Zionist Archive, Jerusalem, Israel.

The Jewish Agency for Israel. (1974). Expansion of Tzur Nathan. [Map]. (S126M6611). Central Zionist Archive, Jerusalem, Israel.

The Jewish Agency for Israel. (1980). Tzur NathanCancelation of plan. [Map]. (S126M6611). Central Zionist Archive, Jerusalem, Israel.

The Jewish Agency for Israel. (1981). Mitzpe Katzir. Israel Land Administration, Tel Aviv, Israel.

The Jewish Agency for Israel, \& World Zionist Organisation. (1981). Temporary site of Harish. [Map]. (S126M6611). Central Zionist Archive, Jerusalem, Israel.

The Jewish Agency for Israel, \& World Zionist Organisation. (1984). Outline plan for Kibbutz Harish. [Map]. Central Zionist Archive, Jerusalem, Israel.

The Jewish Agency for Israel, \& World Zionist Organisation. (1989). Nahal Eron project. [Strategic plans]. Books and Reports Collection (BK\71682\C). Central Zionist Archive, Jerusalem, Israel.

Turner, F. J. (1962). The frontier in American history. Holt, Rinehart \& Winston.

Tznovar Consultants. (1993). Populating Harish Katzir. [Policy report]. Ministry of Interior (ISA-MOINInteriorLocalgov-000hhvo). Israel State Archive, Jerusalem, Israel.

Tzur, S. (2018, November 24). Hamashikim beharish kanu dirot aval hasochrim lo bau: ma koreh lehavtahat hanadlan shel hamedina [Investors in Harish bought apartments, but tenants did not come: What happened to the state's real estate promise]. Globes. https://www.globes.co.il/news/article.aspx?did= 1001261827

Weiss, H. (2011). Immigration and West Bank settlement normalization. PoLAR: Political and Legal Anthropology Review, 34(1), 112-130. https://doi.org/ 10.1111/j.1555-2934.2011.01142.x

Weizman, E. (2006). Principles of frontier geography. In P. Misselwitz, T. Rieniets, Z. Efrat, R. Khamaisi, \& R. Nasrallah (Eds.), City of collision (pp. 84-92). Birkhäuser.

Wolfe, P. (2006). Settler colonialism and the elimination of the native. Journal of Genocide Research, 8(4), 387-409. https://doi.org/10.1080/ 14623520601056240

Yacobi, H., \& Tzfadia, E. (2018). Neo-settler colonialism and the re-formation of territory: Privatization and nationalization in Israel. Mediterranean Politics, 24(1), 1-19.

Yiftachel, O. (1996). The internal frontier: Territorial control and ethnic relations in Israel. Regional Studies, 30(5), 493-508. 


\section{About the Author}

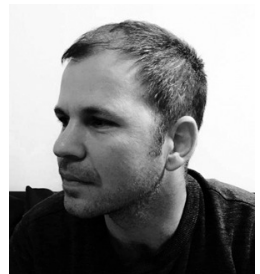

Gabriel Schwake is an architect, historian, and researcher. He is a Fritz Thyssen postdoctoral fellow at TU Delft and a visiting researcher at the University of Cambridge. Gabriel is the author of Dwelling on the Green-Line (Cambridge University Press, 2022) and several articles discussing housing, privatisation, and territoriality. 